\title{
COMPARING TRAFFIC PERFORMANCES OF TURBO- ROUNDABOUTS AND CONVENTIONAL ROUNDABOUT (CASE STUDY)
}

\author{
Amir Izadi \\ $\mathrm{PhD}$ in Road Infrastructure Engineering, Assistant Professor, Department of Civil Engineering, \\ Shomal University of Amol, Amol, Mazandaran, Iran \\ Danial Mirzaiyan \\ M.Sc Student in Transportation Engineering, Department Of Civil Engineering, Iran University Of \\ Science And Technology, Narmak, Tehran, Iran \\ d_mirzaiyan@civileng.iust.ac.ir \\ Abbas Rashidi \\ M.Sc in Transportation Engineering, Department Of Civil Engineering, Iran University Of Science \\ And Technology, Narmak, Tehran, Iran \\ Mohsen Hosseini \\ PhD Student, in Transportation Engineering, Department Of Civil Engineering, Iran University Of \\ Science And Technology, Narmak, Tehran, Iran
}

\begin{abstract}
Research conducted by Yperman and Immers in 2003 shows that the new geometry of these roundabouts, limits "wavelike-movements" and by convincing the driver to use a maximum of 2 lines, provides increasing capacity from $12 \%$ to $20 \%$ in the rotation (island) [4]. According to studies done on a especial case, by Lenin A.Bulla and William Castro, the results showed $7 \%$ increase of capacity in Turbo-roundabouts in comparison with the typically roundabouts[5].In terms of capacity, the results are not consensual. Some authors, using simplified approaches, concluded that turbo-roundabouts offer better capacity than conventional roundabouts of similar size. The application of a new lanebased method reveals that only in very specific scenarios that are uncommon in real-world networks can a standard turbo-roundabout be expected to provide more capacity than the equivalent two-lane roundabout.
\end{abstract}

Keywords: traffic, turbo-roundabout, conventional roundabout

\section{INTRODUCTION}

Roundabouts are often have high traffic volume. it requires a more complex design for easy passage of the traffic flow. In the current two-track vehicles crossing roundabouts, vehicle are forced to slow down according to a geometric curvature and size of the central island, which is one of the common problems related to driver behavior along the way passing. Due to transmission lines being apart, or lack of the use of signs for route selection, the possibility of lane-changing comes up, that the percentage of side-by-side encounters increase and reduce road safety [3].

In order to reduce these problems, a new concept called the Turbo-roundabout was introduced in the Netherlands in 1996 by lambertus Fortujin, which often directional flows separated by physical separations.

For these reasons, drivers have to choose their own route before entering roundabouts, so the potential of collision reduce and safety of route goes up [4]. 
Compared to conventional schemes, the main advantages of a turbo roundabout are:

- limited number of potential conflict points among vehicular trajectories; (which you can see in Figure 1)

- slower speed along the ring;

- low risk of side-by side accidents.

The main disadvantages are:

- presence of through conflict points in left-turning maneuvers (see Fig. 2);

- higher values of the critical gaps along the road, and left-turning maneuvers;

- generally lower capacity than conventional double lane roundabouts [5].

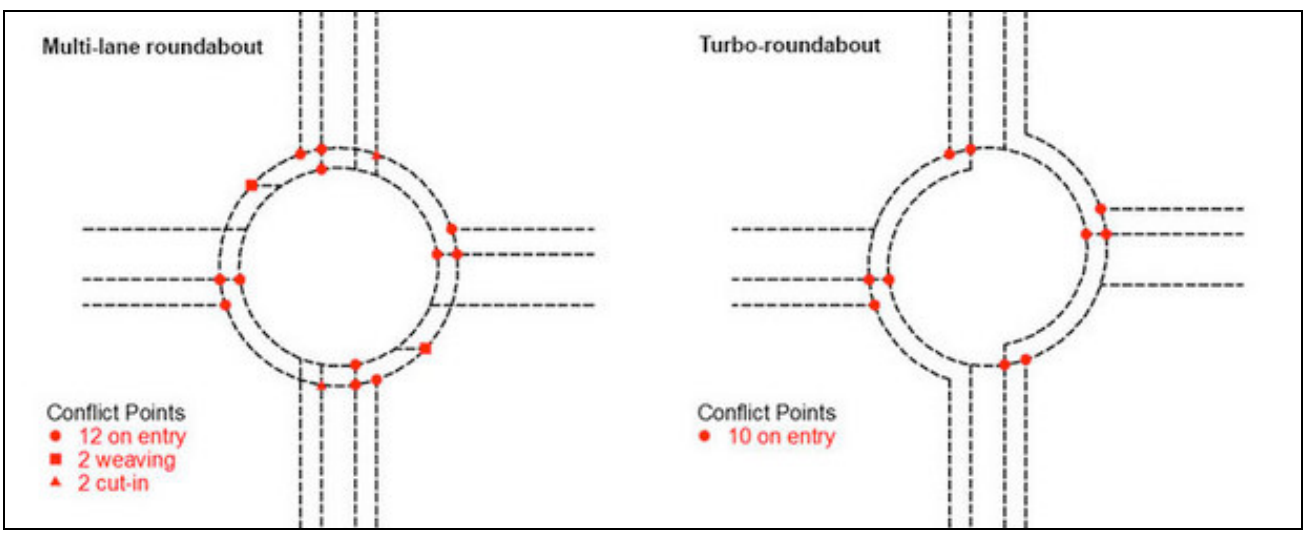

Figure 1. limited number of potential conflict points

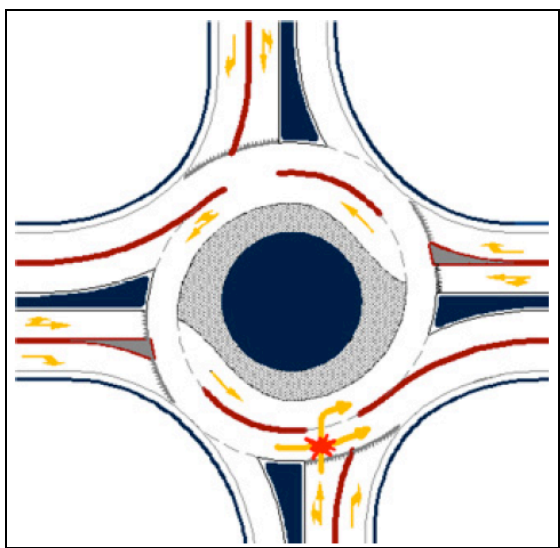

Figure 2. Conflict points in left-turning maneuvers

Research conducted by Yperman and Immers in 2003 shows that the new geometry of these roundabouts, limits "wavelike-movements" and by convincing the driver to use a maximum of 2 lines, provides increasing capacity from $12 \%$ to $20 \%$ in the rotation (island) [4]. According to studies done on a especial case, by Lenin A.Bulla and William Castro, the results showed $7 \%$ increase of capacity in Turbo-roundabouts in comparison with the typically roundabouts[5].In terms of capacity, the results are not consensual. Some authors, using simplified approaches, concluded that turbo-roundabouts offer better capacity than conventional roundabouts of similar size. The application of a new lanebased method reveals that only in very specific scenarios that are uncommon in real-world networks can a standard turbo-roundabout be expected to provide more capacity than the equivalent two-lane roundabout.

According to studies in terms of safety by Raffaele Mauro and Macro Cattani, the results appear to have great significance: in the different layouts and traffic conditions analyzed, turbo-roundabouts 
provide reductions of the number of total potential accidents between $40 \%$ and $50 \%$, and reductions of the number of potential accidents with injuries between $20 \%$ and $30 \%$. The RSA developed a process that allowed concluding and ratifying the road safety benefits in turbo roundabouts. There was a $22 \%$ reduction found in overall risk assessment obtained by the comparison of the average risk of both intersection [5].

To evaluate and compare the performance of typically roundabouts with turbo-roundabouts parameters such as delay time, time travel, the length of the queue created in the entering and stop time is used. One major reason for this is the difficulty to model roundabouts using simulation software. Not many simulation software are flexible enough to allow the user to model roundabouts. VISSIM ( is one of the few simulation software that can be used to model roundabouts. Compare two roundabout was in VISSIM , the turbo-roundabout layout is based on the two-lane roundabout geometry. In the first case the existing roundabout was simulated in software, which input and output volumes has been counted separately. Counting the number of vehicles done by 6 cameras, 4 of which was placed at the highest point of the surrounding buildings and 2 cameras were inside the roundabout. Cars counting time done from 12:00 noon to 13:00 pm for seven days that simulated volume is 7-day average was counted in each direction as shown in the following tables and figures.

Table 1- Entering Volume in Each Direction in Peak Hour

\begin{tabular}{|c|c|}
\hline $\begin{array}{c}\text { Entering Volume in Peak } \\
\text { Hour }\end{array}$ & \multicolumn{1}{c|}{ Flow direction } \\
\hline 1106 & Total incoming from North \\
\hline 483 & Incoming (North to West) \\
\hline 158 & Incoming (North to South) \\
\hline 461 & Incoming (North to East) \\
\hline 1803 & Total incoming from West \\
\hline 260 & Incoming (West to South) \\
\hline 889 & Incoming (West to East) \\
\hline 654 & Incoming (West to North) \\
\hline 1482 & Total incoming from South \\
\hline 140 & Incoming (South to East) \\
\hline 397 & Incoming (South to North) \\
\hline 945 & Incoming (South to West) \\
\hline 1584 & Total incoming from East \\
\hline 185 & Incoming (East to North) \\
\hline 1009 & Incoming (East to West) \\
\hline 390 & Incoming (East to South) \\
\hline
\end{tabular}



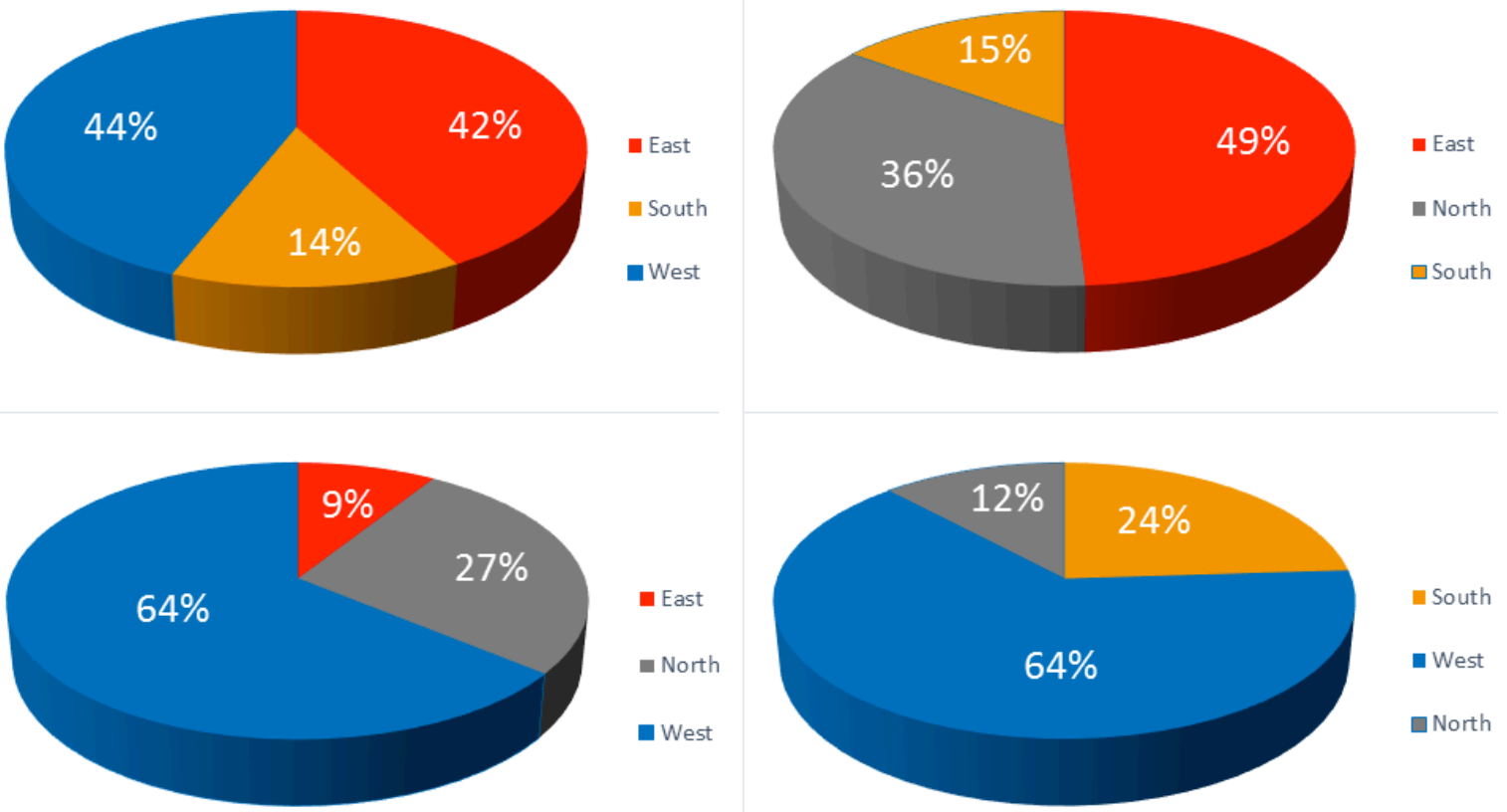

Figure 3. Distribution Incoming Traffic from Each Direction of Roundabout to three other approaches (Percent)

In the next step, turbo-roundabout simulation was performed with taking into account the characteristics of the main roundabout, geometry and volumes of input and output for each direction, and the results are compared. Screenshot from Auto CAD layout for turbo-roundabout and conventional roundabout given in figures 4 and 5 respectively.

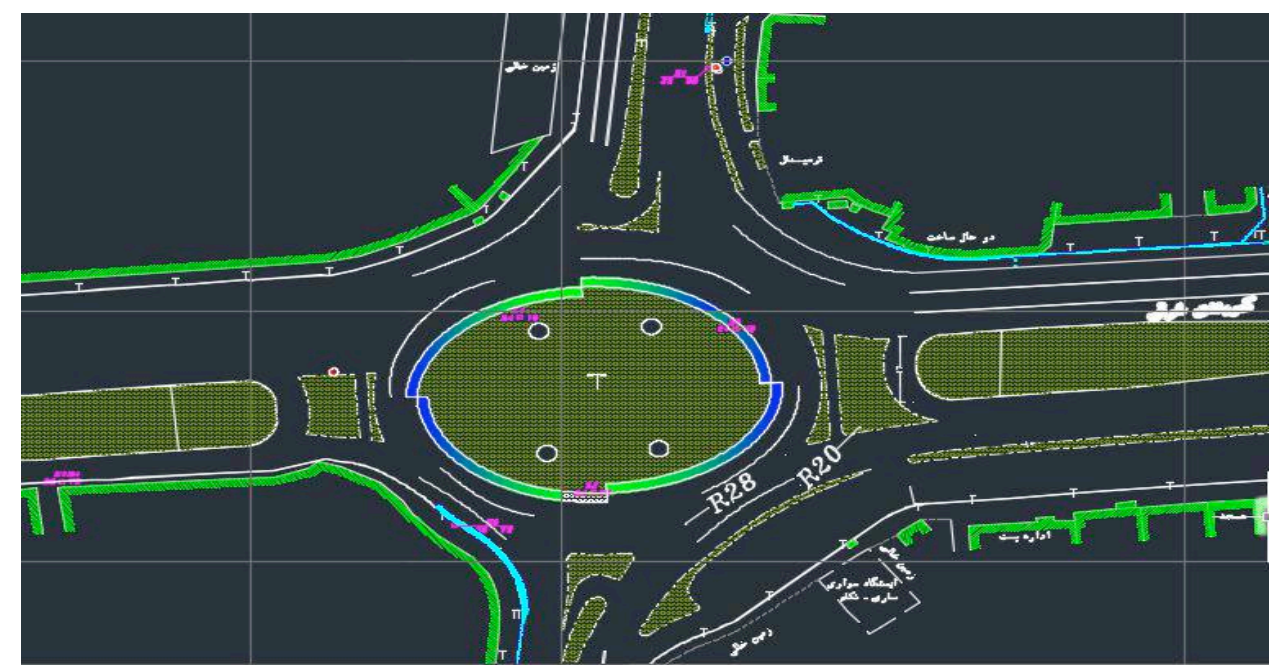

Figure 4. Turbo Roundabout 


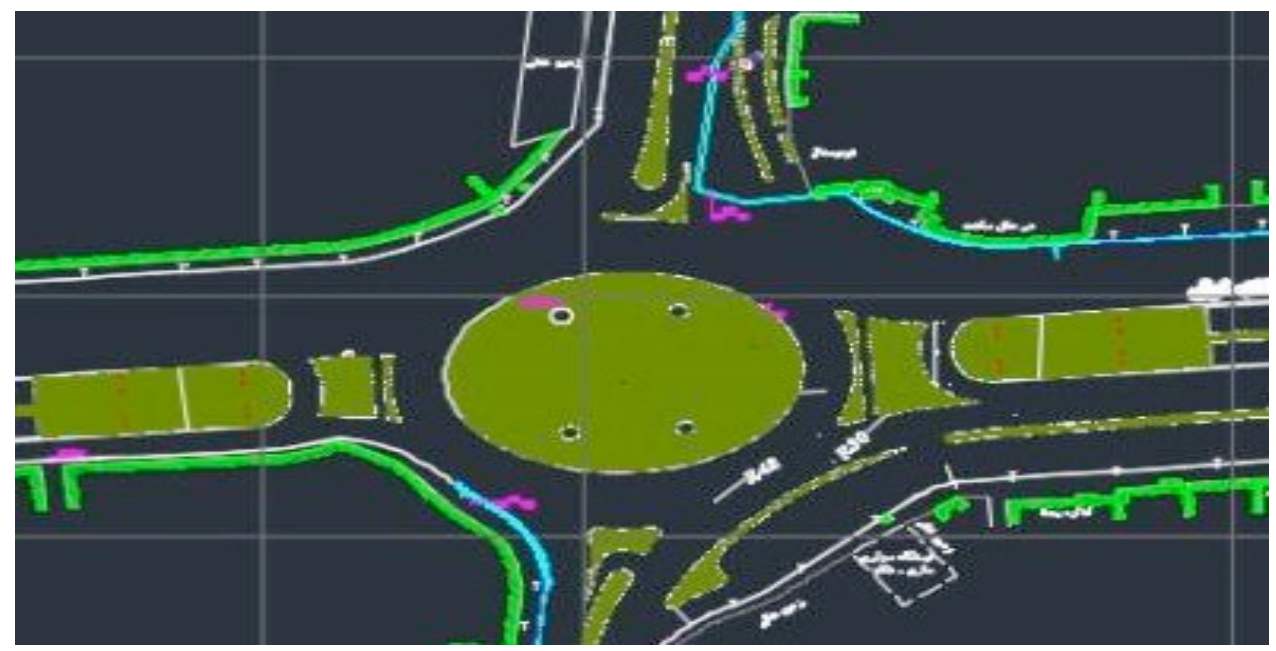

Figure 5. Conventional Roundabout

To optimize the results of software simulation, 10 repetition has been considered and results are the average of the replications.
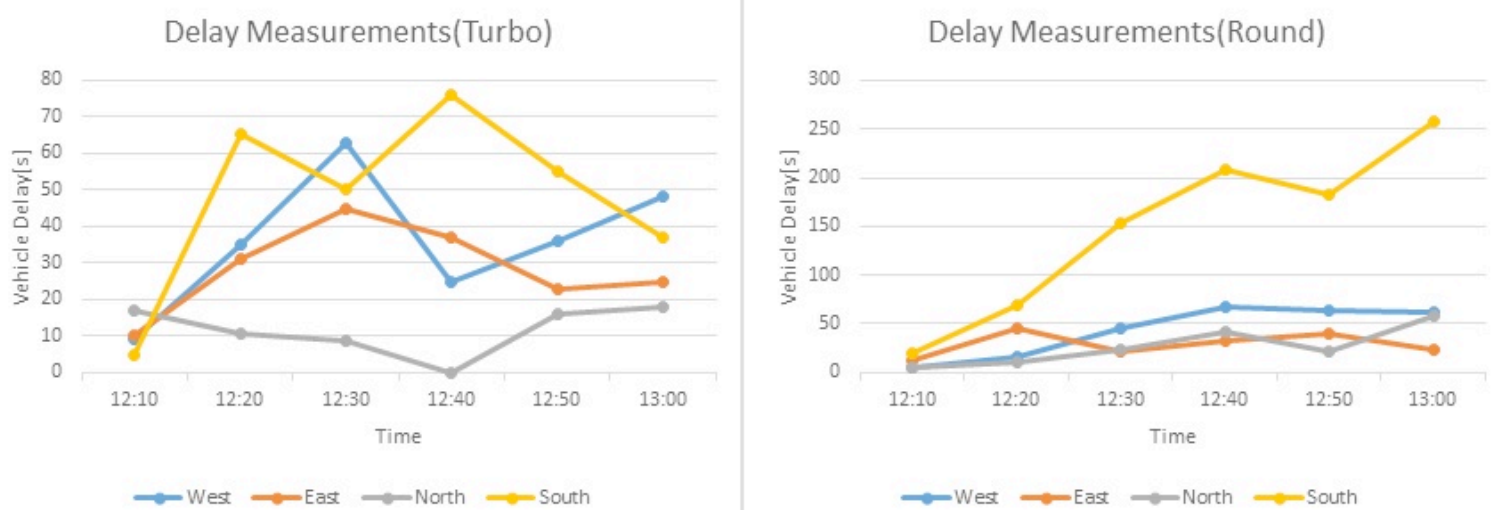

Figure 6. Delay Measurements for Turbo and Conventional Roundabout
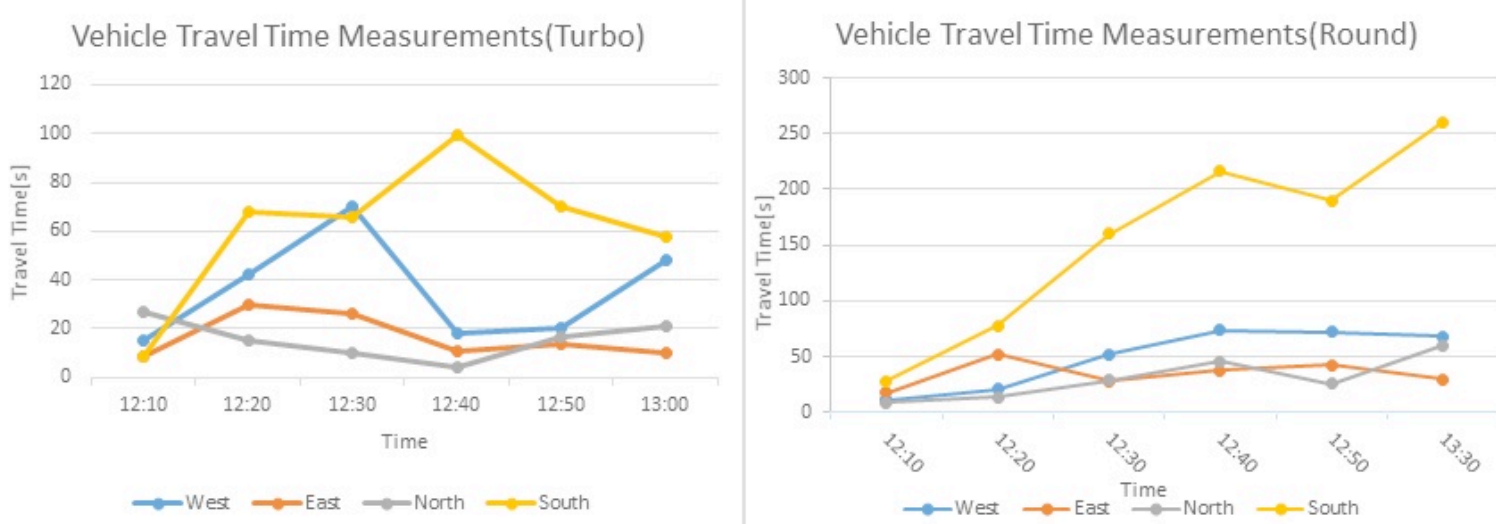

Figure 7. Travel Time Measurements for Turbo and Conventional Roundabout 

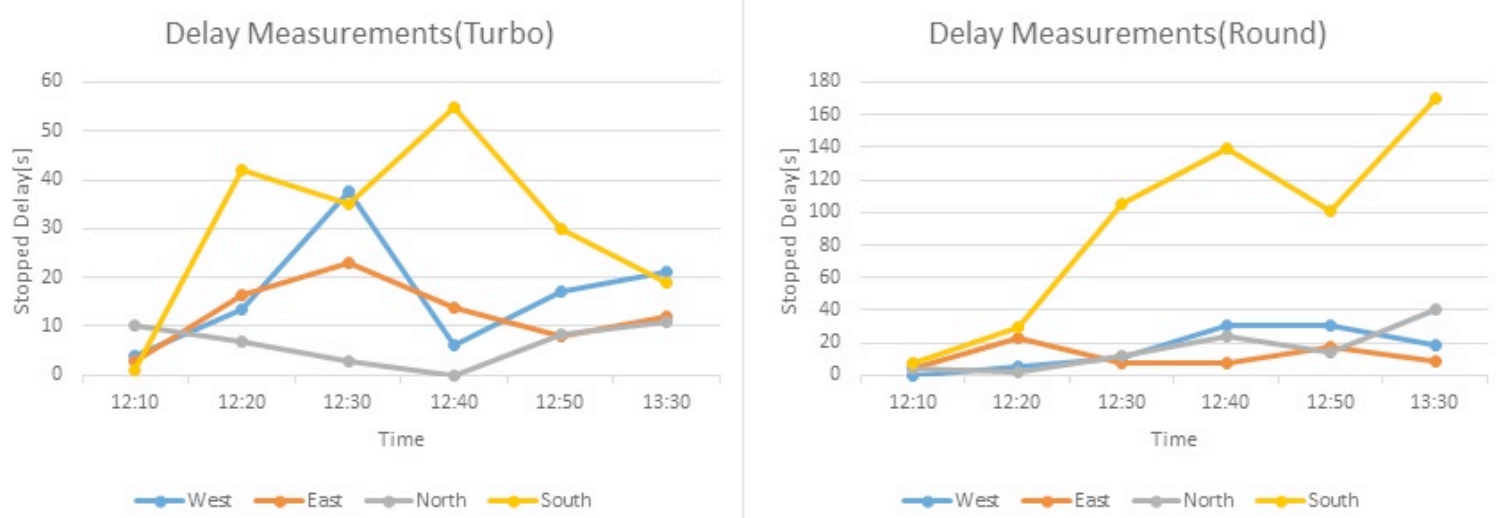

Figure 8. Stopped Delay Measurements for Turbo and Conventional Roundabout
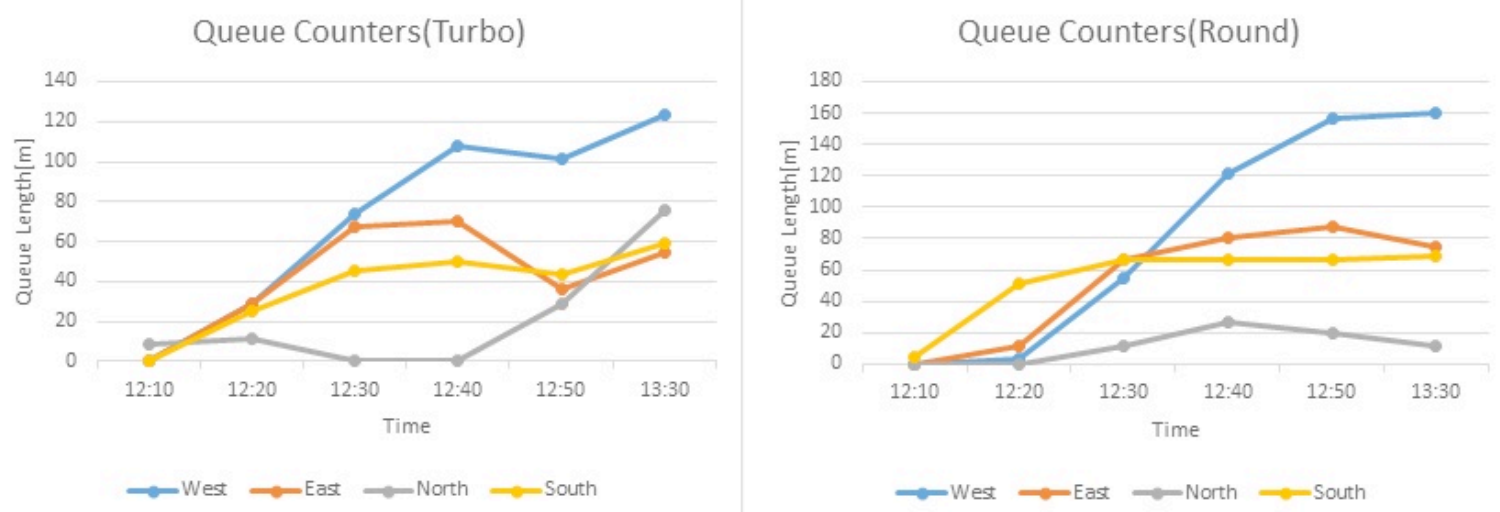

Figure 9. Queue Length Measurements for Turbo and Conventional Roundabout

Table 2. changes ratio

\begin{tabular}{|c|c|c|c|c|}
\hline \multirow{2}{*}{$\begin{array}{c}\text { Comparison } \\
\text { parameters }\end{array}$} & \multicolumn{4}{|c}{ Changes ratio between turbo-roundabout and typically roundabout } \\
\cline { 2 - 5 } & West & East & North & South \\
\hline Delay Time(s) & 1.199 & 1.017 & 2.314 & 3.091 \\
\hline $\begin{array}{c}\text { Vehicle Travel } \\
\text { Time(s) }\end{array}$ & 1.395 & 2.100 & 1.957 & 2.515 \\
\hline Stopped Delay(s) & 0.959 & 0.888 & 2.417 & 3.033 \\
\hline Queue length(m) & 1.140 & 1.245 & 0.548 & 1.450 \\
\hline
\end{tabular}

\section{CONCLUSIONS}

Turbo-roundabout due to the channelization, not only reduce the number of collisions, but decrease side by side accidents as well. We have to pay attention to the fact that the improvement in the condition with the use of turbo-roundabout, is largely dependent upon the driving culture of the region [6].

According to the tables which mentioned before, with comparison between the turbo-roundabout indices and normal roundabout is observed that in most cases and in many directions turbo-roundabout is superior. So that, for the time delay in the West $19.9 \%$, for East $1.7 \%$, for North $131.4 \%$ and for south $209.1 \%$ Turbo is superior in comparison with normal roundabout. The reason for this, in the south side are the small crossing width, and existing the taxi station which can lead to a great deal of interference, which can be addressed with the use of turbo-roundabouts, and also movements can be avoided. 
For the time travel in different directions, Turbo-roundabout has shown $39.5 \%, 95.7 \%, 110 \%$ and $151.5 \%$ reduction in the West, North, East and South respectively than normal roundabout which also, like the first case, due to reasons above, in the south direction we can have the most decrease in the travel time.

For the stop time use of turbo-roundabout instead of the typical roundabout shows, $4.1 \%$ increase in the West, $11.2 \%$ increase in the East, $141.7 \%$ reduction the north, and $203.3 \%$ reduction in the South regarding the stopping time, we have to consider the fact that with the increasing capacity more in the south and north directions compared to two other directions, and with making the travel of cars more convenient in these directions (south and north), the entrance of car into roundabout from east and west would be slower, and this will lead to a greater stopping time in the east and west directions of turbo-roundabout compared to normal ones.

As for the length of the queue created in Turbo-roundabout in comparison to normal roundabout in the North, 45.2\% increase and in the West, East and South 14\%, 24.5\% and $45 \%$ has been reduced respectively. For the length of queue, as we expected, the most decrease is in the south direction, which is the most critical and the most crowded direction proportional to the number of entrance lines. However, the $42.5 \%$ increase in the north direction, considering the improvement of entrance condition from this direction to the roundabout shows that the performance of turbo-roundabouts is largely depend upon how we use it, and due to large volume of input from different directions into west, the length of queue in the roundabout, for the direct entrance to the roundabout has increased.

As can be seen in the majority of cases compared, turbo-roundabout is superior, and in the south, the incoming traffic volume of which is high and number of entering line to roundabout is low, a significant improvement has been achieved. As a topic for future researches, we can compare fuel usage, and green-house gases emission in turbo-roundabouts and normal roundabouts, with the use of simulation soft wares like VISSIM.

\section{REFERENCES}

Giuffrè O.a, Granà A., Marino S.a. ( 2012 ). Turbo-roundabouts vs Roundabouts Performance Level. SIIV - 5th International Congress - Sustainability of Road Infrastructures

A. Vasconcdos, A. Seco, A. Silva. (2011). Capacity of Normal and Turbo-round about. Comparative Analysis. Institution of Civil Engineers.

Ferdinando Corriere and Marco Guerrieri.(2012). Performance Analysis of Basic Turbo-Roundabouts in Urban Context. $5^{\text {th }}$ International Congress - Sustainability of Road Infrastructures.

VISSIM 3.70 User Manual. PTV Planung Transport Verkehr AG: Karlsruhe, Germany, 2003

Lenin A.Bulla and William Castro. (2011). Analysis and Comparison Between Two-Lane Roundabouts and Turbo-Roundabouts Based on Road Safety Audit Methodology and Microsimulation : A Case Study In Urban Area. $3^{\text {rd }}$ International Conference on Road Safety and Simulation.

Andrighettoni, C. and R., Mauro. Un nuovo tipo di incrocio a rotatoria [A new type of roundabout] -e Strade, Ed. La Fiaccola, Milano, vol. 1/2, N.1434, 2008, pp. 17-23. ISSN: 0373-2916. 